\title{
Passive smoking and respiratory conditions in primary school children
}

\author{
SHEENA M SOMERVILLE, ROBERTO J RONA, AND SUSAN CHINN \\ From the Department of Community Medicine, United Medical and Dental Schools of Guy's and St Thomas's \\ Hospitals, St Thomas's Campus, London SE1 7EH
}

SUMMARY The effect of passive smoking on respiratory symptoms of children aged 5 to 11 years was investigated in over 4000 English children and nearly 800 Scottish children participating in the National Study of Health and Growth in 1982. After adjusting for associations of respiratory symptoms with age, sex, and a number of potentially confounding variables, significant associations were found of wheeze, both occasional and persistent, day or night cough, and bronchitis attacks with number of cigarettes smoked by parents at home for English children and for occasional wheeze in Scottish children. Asthma attacks and cough first thing in the morning showed positive but not statistically significant associations in English children. The presence of at least one condition was statistically significant in both English and Scottish children. The largest relative risk for exposure to 20 cigarettes a day compared to no exposure was 1.60 for persistent wheeze in English children (95\% confidence interval $1 \cdot 17-2 \cdot 18)$.

Among the harmful effects postulated for passive smoking is a possible association between parental smoking and respiratory conditions in children, which has been investigated in a large number of studies. A review article ${ }^{1}$ concluded that the studies were consistent in suggesting increased infections in children under 1 year of age but inconsistent in older children. As almost all found some effect of parental smoking, the latter conclusion seems to have been due to the lack of a significant dose-response relation in just over half the studies considered.

The studies on older children have varied in the symptoms studied, in the age range of the children, in the proportion of parents who smoked, and in the potentially confounding variables that have been taken into account. A report of a workshop on the effect of passive smoking on children ${ }^{2}$ listed nine groups of such variables that it is desirable to take into account. No study has included all of these, and most included only a few variables in one or two of the listed groups. This can be attributed largely to the fact that $\mathrm{few}^{2}$ of the studies were designed to investigate passive smoking effects, and were opportune analyses on data collected mainly to investigate the relations in children between symptoms and lung function and a variety of environmental factors.

Of even more importance to the detection of a dose-response relation the studies have differed markedly in size and in the measure of passive smoking. The most usual measure was the number of parents smoking, providing lower power to detect a dose-response relation than a measure of the amount smoked. A recent review ${ }^{3}$ reported only three studies of young children in which the measure of passive smoking was cigarettes smoked per day, and just one study of older children.

The National Study of Health and Growth, an on-going surveillance study of the health and growth of primary school children in England and Scotland, was also not designed to investigate passive smoking effects. Data on the number of smokers of five or more cigarettes a day in the child's home were collected in 1977 as a confounding variable in a study of the relation of respiratory illness and outdoor air pollution. ${ }^{4}$ These data also suggested a negative relation of child's height to number of smokers in the home after adjusting for birthweight. ${ }^{5}$ In order to study this association further, data on the number of cigarettes smoked at home by each parent, and by the mother during pregnancy, were collected in $1982 .{ }^{6}$ No data on lung function were obtained.

Further examination of the 1977 data on English and Scottish children showed a number of statistically significant positive associations of respiratory symptoms with the number of smokers. Given the reasonable sample size, the availability of data for a 
Table 1 Number of children for whom data on each respiratory condition were obtained and the prevalence (\%) of each condition, by sex and country

\begin{tabular}{|c|c|c|c|c|c|c|c|c|}
\hline \multirow[b]{3}{*}{ Respiratory condition } & \multicolumn{4}{|c|}{ England } & \multicolumn{4}{|c|}{ Scotland } \\
\hline & \multicolumn{2}{|l|}{ Boys } & \multicolumn{2}{|l|}{ Girls } & \multicolumn{2}{|l|}{ Boys } & \multicolumn{2}{|l|}{ Girls } \\
\hline & No. & $\begin{array}{l}\text { Prevalence } \\
\%\end{array}$ & No. & $\begin{array}{l}\text { Prevalence } \\
\%\end{array}$ & No. & $\begin{array}{l}\text { Prevalence } \\
\%\end{array}$ & No. & $\begin{array}{l}\text { Prevalence } \\
\%\end{array}$ \\
\hline Chest EVER sound wheezy or whistling & 3063 & $12 \cdot 6$ & 2870 & $9 \cdot 5$ & 572 & $13 \cdot 1$ & 563 & $6 \cdot 9$ \\
\hline $\begin{array}{l}\text { Chest wheezy or whistling on } \\
\text { MOST days or nights }\end{array}$ & 3046 & $3 \cdot 2$ & 2858 & $2 \cdot 6$ & 569 & $4 \cdot 4$ & 564 & $2 \cdot 8$ \\
\hline $\begin{array}{l}\text { In the last } 12 \text { months had: } \\
\text { Bronchitis attack(s) } \\
\text { Asthma attack(s) }\end{array}$ & $\begin{array}{l}3030 \\
3060\end{array}$ & $\begin{array}{l}4 \cdot 0 \\
4 \cdot 2\end{array}$ & $\begin{array}{l}2852 \\
2862\end{array}$ & $\begin{array}{l}2 \cdot 7 \\
2 \cdot 8\end{array}$ & $\begin{array}{l}570 \\
568\end{array}$ & $\begin{array}{l}3 \cdot 5 \\
2 \cdot 3\end{array}$ & $\begin{array}{l}565 \\
567\end{array}$ & $\begin{array}{l}2 \cdot 1 \\
2 \cdot 1\end{array}$ \\
\hline Usually coughs first thing in the morning & 3048 & $4 \cdot 2$ & 2851 & $4 \cdot 5$ & 569 & $5 \cdot 1$ & 558 & $5 \cdot 0$ \\
\hline Usually coughs during the day or at night & 3036 & 8.3 & 2858 & 7.8 & 568 & $11 \cdot 1$ & 560 & $8 \cdot 4$ \\
\hline
\end{tabular}

number of potentially confounding variables, and the almost unique data on amount of smoking in the home, it was decided to investigate the dose-response relation of symptoms to passive smoking, using the 1982 data, in children aged 5 to 11 years.

\section{Methods}

In 1982 children took part in the study in 22 areas in England and five in Scotland. Data on the child's respiratory symptoms, parental smoking, and family background were obtained from a self-administered questionnaire completed by the child's mother. Triceps skinfold thickness was measured as described elsewhere ${ }^{7}$ and was included in the analysis as previously $^{8}$ a relation had been shown between respiratory symptoms and this measure of obesity.

Each of six respiratory symptoms or illnesses, given in table 1, was analysed as a dichotomous, ie, present or absent, dependent variable using logistic regression. Any child with a missing value was excluded from the analysis of that symptom. The number of cigarettes smoked per day at home by the mother and father in total, the passive smoking component, and the number of cigarettes smoked per day by the mother during pregnancy with the child were each included as a quantitative variable. Two groups of potentially confounding variables were included in the regression analyses, those treated as quantitative variables and those that were categorical variables. The former group consisted of the child's age, birthweight, triceps skinfold thickness expressed as a standard deviation score, ${ }^{7}$ mother's age, and number of siblings. The categorical variables were: child's sex; father's social class, in four groups as non-manual, skilled manual, semi-skilled or unskilled manual, or other; father employed, unemployed or not known; child in oneparent family, two-parent, or not known; presence or absence of household overcrowding, defined as a ratio of people in the household to number of rooms of at least 1-25; mother's education as highest full-time level in seven groups, none or primary only, secondary or comprehensive school, grammar, technical or commercial college, university, other, or not known. Except as stated missing data excluded a child from the analysis.

Analyses were carried out with all these as independent variables and also with just parental smoking, age, and sex as the independent variables, for England and Scotland separately, and for the two countries combined. Analyses were also carried out for each sex separately and, using the fully adjusted model, with the dependent variable as presence of at least one of the respiratory conditions.

\section{Results}

In 1982 there were 8118 children eligible to take part in the study; a questionnaire was returned for $87.8 \%$ of these children.

Table 2 Distribution of cigarettes smoked per day by parents at home in England and Scotland

\begin{tabular}{|c|c|c|}
\hline \multirow{2}{*}{$\begin{array}{l}\text { No. of cigarettes } \\
\text { (total smoked by father and mother) }\end{array}$} & \multicolumn{2}{|l|}{$\%$ of parents } \\
\hline & England & Scotland \\
\hline $\begin{array}{l}0 \\
\leqslant 4 \\
5-14 \\
15-24 \\
25-34 \\
\geqslant 35\end{array}$ & $\begin{array}{r}57.9 \\
3.4 \\
16.9 \\
12.4 \\
5.2 \\
4.2\end{array}$ & $\begin{array}{r}39.9 \\
3.0 \\
19.9 \\
19.7 \\
9.2 \\
8.4\end{array}$ \\
\hline $\begin{array}{l}\text { No of children whose parents } \\
\text { are included in this table }\end{array}$ & $5169(100 \%)$ & $928(100 \%)$ \\
\hline
\end{tabular}


Table 3 Results of logistic regression analyses for England showing the association between respiratory symptoms and passive smoking" from the fully adjusted model

\begin{tabular}{|c|c|c|c|}
\hline \multirow{3}{*}{$\begin{array}{l}\text { Respiratory symptom } \\
\text { Chest EVER sound wheezy or whistling }\end{array}$} & \multicolumn{3}{|c|}{ Regression coefficient \pm standard error } \\
\hline & $\begin{array}{l}\text { Boys } \\
(N=2181 \text { to 2246) }\end{array}$ & \multirow{2}{*}{$\begin{array}{l}\begin{array}{l}\text { Girls } \\
(N=2074 \text { to 2128) }\end{array} \\
0.014^{+} \pm 0.008\end{array}$} & $\begin{array}{l}\text { All children } \\
(N=4255 \text { to } 4371)\end{array}$ \\
\hline & \pm 0.007 & & $0.011^{*} \pm 0.005$ \\
\hline Chest wheezy or whistling MOST days or nights & $0.037^{* *} \pm 0.011$ & $0.010 \pm 0.013$ & $0.024^{* *} \pm 0.008$ \\
\hline $\begin{array}{l}\text { In the last } 12 \text { months had: } \\
\text { Bronchitis attack(s) } \\
\text { Asthma attack(s) }\end{array}$ & $\begin{array}{l} \pm 0.012 \\
\pm 0.012\end{array}$ & $\begin{array}{l}0.033^{*} \pm 0.013 \\
0.026^{+} \pm 0.013\end{array}$ & $\begin{array}{ll}0.018^{*} & \pm 0.008 \\
0.009 & \pm 0.009\end{array}$ \\
\hline Usually coughs first thing in the morning & \pm 0.012 & $0.022^{*} \pm 0.011$ & \pm 0.008 \\
\hline Usually coughs during the day or at night & \pm 0.008 & $0.020^{*} \pm 0.008$ & $0.013^{*} \pm 0.006$ \\
\hline At least one condition & \pm 0.006 & \pm 0.007 & $0.009^{*} \pm 0.005$ \\
\hline
\end{tabular}

$+p<0.1 \quad * p<0.05 \quad * p<0.01$

\# parental smoking defined as the total number of cigarettes smoked at home by mother and father together.

PREVALENCE OF RESPIRATORY CONDITIONS Table 1 shows the number of children for whom data were obtained on each respiratory condition, which varied from $86 \cdot 4 \%$ to $87 \cdot 1 \%$ of the total eligible, and the percentage with each condition, by sex and country. The prevalence of each condition was greater in boys than in girls but differed little between England and Scotland.

\section{DISTRIBUTION OF PASSIVE SMOKING}

Data on parental smoking were available for $75 \cdot 1 \%$ of children. The distributions of the number of cigarettes smoked per day by the parents at home are given in table 2 for children in England and Scotland. Smoking by parents was more prevalent in Scotland than in England.

RELATION OF RESPIRATORY CONDITIONS TO PASSIVE SMOKING

After exclusions for missing data, primarily in respiratory symptoms or parental smoking, the number of children available ranged from 4337 $(63.4 \%)$ to $4371(63.9 \%)$ for England and from 766 $(60.90 \%)$ to $771(61 \cdot 3 \%)$ for Scotland. Table 3 shows the relation of six respiratory conditions to passive smoking for English children as estimated from the logistic regression analysis, adjusted for all the potentially confounding variables listed above. For all children parental smoking was most strongly positively associated with 'chest wheezy or whistling on most days or nights' $(p<0.01)$ and also significantly associated $(\mathrm{p}<0.05)$ with 'usually coughs during the day or night', 'chest ever sounds wheezy or whistling', and bronchitis attacks in the last 12 months. The relation was positive for the other two conditions. Although results appeared to show some differences between boys and girls, no significant difference, as assessed from an interaction term in the model, was found in the relation of passive smoking except for asthma $(p<0.05)$, which showed a positive association $(\mathrm{p}<0.1)$ with parental smoking in girls, and a non-significant negative relation in boys. The relation of prevalence of at least one of the conditions was just significant $(p<0.05)$ for all English children.

For Scottish children, who were fewer in number than the English children, the only significant relation of an individual condition to parental smoking was found for 'chest ever wheezy' $(p<0.01)$. However the prevalence of at least one condition was significantly related to parental smoking $(p<0.05)$.

Results are given for England and Scotland separately as the relation of 'chest ever wheezy' and 'wheeze most days or nights' to passive smoking was found to differ significantly between the two countries $(p<0.05)$. 'Wheeze most days or nights' showed a relation to passive smoking only in England, whereas 'chest ever wheezy' showed a stronger relation to passive smoking in Scottish children than in English, of similar size to that for persistent wheeze in English children.

\section{EFFECTS OF ADJUSTMENT FOR CONFOUNDING VARIABLES}

Table 4 shows the relation between passive smoking and each respiratory condition adjusted only for age for boys and girls separately, and for age and sex for all English children. Comparison with table 3 shows that in most cases adjustment for the potentially confounding variables generally increased the standard errors so there was a reduction in statistical significance, the notable exceptions being 'chest wheezy or whistling most days or nights' in boys, and bronchitis attacks in girls for which the regression coefficient increased considerably on adjustment. For 
Table 4 Results of logistic regression analyses for England showing the association between respiratory symptoms and parental smoking for the model adjusted only for age (and sex for all children)

\begin{tabular}{|c|c|c|c|c|c|}
\hline \multirow{3}{*}{$\begin{array}{l}\text { Respiratory symptom } \\
\text { Chest EVER sound wheezy or whistling }\end{array}$} & \multicolumn{5}{|c|}{ Regression coefficient \pm standard error } \\
\hline & $\begin{array}{l}\text { Boys } \\
(N=2181 \text { to } 2246)\end{array}$ & \multicolumn{2}{|c|}{$\begin{array}{l}\text { Girls } \\
(N=2074 \text { to 2128) }\end{array}$} & \multicolumn{2}{|c|}{$\begin{array}{l}\text { All children } \\
(N=4255 \text { to 4371) }\end{array}$} \\
\hline & $-0.002 \pm 0.006$ & $0.013^{*}$ & \pm 0.006 & 0.005 & \pm 0.004 \\
\hline Chest wheezy or whistling MOST days or nights & $0.023^{*} \pm 0.009$ & $0.033^{* *}$ & \pm 0.009 & $0.028^{* * *}$ & \pm 0.007 \\
\hline $\begin{array}{l}\text { In the last } 12 \text { months had: } \\
\text { Bronchitis attack(s) } \\
\text { Asthma attack(s) }\end{array}$ & $\begin{array}{ll}-0.002 & \pm 0.010 \\
-0.014 & \pm 0.010\end{array}$ & $\begin{array}{l}0.022^{*} \\
0.018^{+}\end{array}$ & $\begin{array}{l} \pm 0.010 \\
\pm 0.010\end{array}$ & $\begin{array}{l}0.008 \\
0.000\end{array}$ & $\begin{array}{l} \pm 0.007 \\
\pm 0.007\end{array}$ \\
\hline Usually coughs first thing in the morning & $0.001 \pm 0.010$ & $0.021^{*}$ & \pm 0.008 & $0.012^{+}$ & \pm 0.006 \\
\hline Usually coughs during the day or at night & $0.015^{*} \pm 0.006$ & $0.026^{* * *}$ & \pm 0.006 & $0.021^{* * *}$ & \pm 0.004 \\
\hline At least one condition & $0.005 \pm 0.005$ & $0.012^{*}$ & \pm 0.006 & $0.008^{*}$ & \pm 0.004 \\
\hline
\end{tabular}

$\mathrm{N}=$ the range of the number of children in the six analyses

$+\mathrm{p}<0.1 \quad \mathrm{p}<0.05 \quad \mathrm{p}<0.01 \quad \mathrm{p}<0.001$

\# See footnote to Table 3.

Table 5 Estimates of prevalence (\%) of respiratory symptoms and relative risk for children ${ }^{*}$ of parents smoking no cigarettes, 10 and 20 cigarettes at home per day, based on the fully adjusted model for all children

\begin{tabular}{|c|c|c|c|}
\hline \multirow{3}{*}{ Respiratory condition } & \multicolumn{3}{|c|}{ Prevalence \% (relative risk compared to non-smoking parents) } \\
\hline & \multicolumn{3}{|c|}{ Cigarettes smoked at home by parents } \\
\hline & 0 & 10 & 20 \\
\hline Chest wheezy or whistling on MOST days or nights & $2 \cdot 8$ & $3.5(1 \cdot 27)$ & $4.5(1.60)$ \\
\hline Bronchitis attack(s) in the last 12 months & 3.9 & $4 \cdot 7(1 \cdot 18)$ & $5.5(1.40)$ \\
\hline Usually coughs during the day or night & $7 \cdot 7$ & $8 \cdot 7(1 \cdot 13)$ & $9.8(1 \cdot 27)$ \\
\hline At least one condition & $17 \cdot 9$ & $19 \cdot 3(1.08)$ & $20 \cdot 8(1 \cdot 16)$ \\
\hline
\end{tabular}

- Given for boys aged 8 years, with no siblings, in a two parent family, father employed and social class IIIB, mother's smoking in pregnancy 0 , home not overcrowded, mother aged 32 and educated at a secondary or comprehensive school, triceps skinfold standard deviation score 0 , birthweight $3000 \mathrm{~g}$.

all Scottish children, adjusting only for age and sex, significant associations were found between passive smoking and 'chest ever wheezy' $(p<0.01)$, 'usually coughs during the day or night' $(p<0.05)$, and prevalence of at least one condition $(p<0.01)$.

\section{ESTIMATES OF RELATIVE RISK}

Table 5 gives examples of prevalence of respiratory conditions and relative risk (in parentheses) estimated from the regression coefficients in the fully adjusted model for the three conditions showing the largest associations with passive smoking in all English children. Compared with children whose parents do not smoke the relative risks were around 1.2 for children whose parents smoke 10 cigarettes a day in total at home, and from 1.3 to 1.6 for those whose parents smoke 20 a day. They are of necessity given for fixed values of the other independent variables but would not differ markedly for different values of these variables. The relative risk of at least one condition is lower, only just significantly different from 1.0 at the $5 \%$ level, but shows the estimated increase in the percentage of children suffering some respiratory symptom at the given levels of parental smoking.

\section{Discussion}

A number of statistically significant positive associations were found between respiratory conditions in children and number of cigarettes smoked per day at home by their parents, but not consistently for all symptoms or in both countries. The result also differed to some extent from those found in the 1977 data, in which the passive smoking variable, number of smokers of at least five cigarettes a day in the home, was significantly associated $(p<0.05)$ with all six conditions except bronchitis in the last 12 months. The analyses of the two years' data differed in the confounding variables taken into account, the use of gas for cooking and population density being 
included in the 1977 analysis, but not maternal smoking in pregnancy or mother's education or age. They were similar in the age range of the children, in sample size, and in the wording of the questions about respiratory conditions.

Inevitably, other studies have differed in the symptoms or illnesses studied and in the exact questions asked. However the largest study with a similar age range, ${ }^{9}$ in which 10106 children aged 6 to 10 years were involved, found highly significant associations $(p<0.001)$ between cough for three months or more of the previous year and wheeze most days or nights with maternal smoking, and a less significant association $(p<0.01)$ of bronchitis with maternal smoking, broadly in line with our findings.

Other studies have also found significant positive associations between persistent cough and parental smoking, ${ }^{10-12}$ and, although not statistically significant, a relative risk of 4.9 for persistent wheeze was found for children exposed to a smoker at home compared to those never exposed in a study of 626 children under 15 years. ${ }^{12}$

The only other study ${ }^{13}$ to include "cough first thing in the morning' found a positive association $(p<0.05)$ in 12 year old girls after allowing for the child's own smoking. Many studies of passive smoking have included non-persistent wheeze, with various definitions, and some asthma or bronchitis. About half of those obtained significant positive associations, and the rest non-significant associations. However, few studies have included all four symptoms of wheeze, cough, asthma, and bronchitis. Apart from the question of prime importance being whether passive smoking causes any harmful effect to children of primary school age, the nature of the effect being a secondary consideration, the symptoms are not manifestations of distinct diseases. Analysis of single symptoms may fail to detect a real increase in the prevalence of a condition. In particular, an effect of passive smoking increasing symptoms of asthma may be missed if only a question about asthma is included due to underdiagnosis in many children with wheeze $^{1415}$ and the fact that cough may be the only presenting symptom. ${ }^{16}$

No data were available on active smoking by the children as the questionnaire was completed by a parent. However, even in the oldest age group and on the assumption that smoking by the child is strongly associated with parental smoking, the prevalence of active smoking would be too small to account for the differences in prevalence of respiratory symptoms. Dobbs and Marsh ${ }^{17}$ reported a prevalence of regular smoking, defined as 'at least one cigarette a week', of $1 \%$ and $0 \%$ in first year secondary school boys and girls respectively, in England in 1982, and 5\% and 3\% in Scotland. Of the groups of other confounding variables that have been suggested ${ }^{2}$ that are relevant to children's symptoms as reported by the mother, those of other indoor pollutants are probably the most important ones not included in the analysis of the 1982 data. In the analysis of 1977 data the use of gas for cooking, an important source of nitrogen dioxide in the home, ${ }^{18}$ did not eliminate positive associations of respiratory symptoms with passive smoking.

Parental symptoms are on the list of potentially confounding variables, ${ }^{2}$ and there is no doubt that a child's symptoms show a relation to these.91012 19 However, as many of the symptoms of smokers will be a result of their smoking, adjustment for parental symptoms could remove a real effect of parental smoking on a child's health. ${ }^{20}$ Of the few studies in which the adjustment had been made the largest ${ }^{9} 20$ still found positive associations between child's cough and wheeze and maternal smoking in over 10000 6-10 year old children. Lebowitz, ${ }^{12}$ in a much smaller study, found statistical significance of an association removed by the adjustment. Schenker $e t a^{19}$ found a positive association between chest illness on at least three days in the last year which persisted on adjustment for parental respiratory disease, but found no association before or after adjustment in chronic cough, phlegm or wheeze in 4000 children aged 5 to 14 .

Studies have varied in the prevalence of respiratory conditions and in the percentage of parents smoking. While low values of either may lead to statistically insignificant results in the presence of a real effect, the most important variation in the studies has been in sample size. The majority of studies provide no information on the amount smoked by parents. For children of two parents who smoke the estimated relative risk of the respiratory conditions studied was less than two compared to children of non-smoking parents in almost all studies. ${ }^{3}$ The conclusion that emerges is that if there is a real effect of passive smoking on the respiratory health of children aged 5 to 11 years, then it is a small one, and a large study is required for a high probability of its detection. Although results for the smaller sample of Scottish children were not significantly different from those for English children, except for wheeze, a significant relation was found only for 'chest ever wheezy' and at least one condition. For English children the largest relative risk was for persistent wheeze, of 1.60 in children whose parents smoked a total of 20 cigarettes a day $(95 \%$ confidence interval $1 \cdot 17-2 \cdot 18)$ and $1 \cdot 16$ $(1.00-1.34)$ for any symptom. The USA six cities study ${ }^{9}$ found a relative risk of 1.3 for persistent wheeze in 6 to 10 year old children whose mothers smoke 20 cigarettes a day.

As the association is probably less strong than that for children under 1 year, it is to be expected that secondary school children would show a weaker, or no 
association of symptoms with passive smoking. We have therefore confined consideration of the literature to studies including broadly similar age groups. All four studies 9132122 that we have identified with an analysis of data for 6000 or more children in a similar age range to those in our 1982 English sample have shown at least one significant positive association with passive smoking. The two largest ${ }^{21} 22$ also showed a dose-response relation. Our data have supported the hypothesis of an effect of parental smoking on children of this age. Scepticism could be removed further only by a study of several symptoms in at least 6000 children, including all potentially confounding variables as recommended, ${ }^{2}$ with a quantitative measure of passive smoking by the child.

We thank Professor W W Holland for his continued support and encouragement, Mrs. A Childs for preparing the manuscript, and all the fieldworkers, nurses, teachers, administrators, parents, and children who take part in the study. The study is funded by the Department of Health and Social Security and the Scottish Home and Health Department.

\section{References}

${ }^{1}$ Guyatt GH, Newhouse MT. Are active and passive smoking harmful? Determining causation. Chest 1985; 88: 445-51.

2 US Department of Health and Human Services. Report of workshop on respiratory effects of involuntary smoke exposure: epidemiologic studies, May 1-3, 1983. USDHHS. National Heart, Lung and Blood Group, 1983.

${ }^{3}$ Surgeon General. The health consequences of involuntary smoking. Rockville, Maryland: USDHHS Office on Smoking and Health, 1986.

${ }^{4}$ Melia RJW, Florey C du V, Swan AV. Respiratory illness in British schoolchildren and atmospheric smoke and sulphur dioxide 1973-7. I: Cross-sectional findings. J Epidemiol Community Health 1981; 35: 161-7.

${ }^{5}$ Rona RJ, Florey C du V, Clarke GC, Chinn S. Parental smoking at home and height of children. Br Med J 1981; 283: 1363.
${ }^{6}$ Rona RJ, Chinn S, Florey C du V. Exposure to cigarette smoking and children's growth. Int J Epidemiol 1985; 14: 402-9.

${ }^{7}$ Chinn S, Rona RJ. The secular trends in weight, weightfor-height and triceps skinfold thickness in primary school children in England and Scotland from 19721980. Ann Hum Biol 1987; 14: 311-9.

${ }^{8}$ Somerville SM, Rona RJ, Chinn S. Obesity and respiratory symptoms in primary school. Arch Dis Child 1984; 59: $940-4$.

${ }^{9}$ Ware JH, Dockery DW, Spiro A, Speizer FE, Ferris BG. Passive smoking, gas cooking, and respiratory health of children living in six cities. Am Rev Respir Dis 1984; 129: 366-74.

${ }^{10}$ Colley JRT. Respiratory symptoms in children and parental smoking and phelgm production. Br Med J 1974; ii: $201-4$.

${ }^{11}$ Dodge $\mathrm{R}$. The effects of indoor pollution on Arizona children. Arch Environ Health 1982; 37: 151-5.

12 Lebowitz MD, Burrows B. Respiratory symptoms related to smoking habits of family adults. Chest 1976; 69: 48-50.

13 Bland M, Bewley BR, Pollard V, Banks MH. Effect of children's and parents' smoking on respiratory symptoms. Arch Dis Child 1978; 53: 100-5.

14 Speight ANP, Hey EN, Lee D. Underdiagnosis and undertreatment of asthma in childhood. $\mathrm{Br}$ Med J 1983; 286: $1253-6$.

15 Anderson HR, Bailey PA, Cooper JS, Palmer JC, West S.o Medical care of asthma and wheezing illness in children: 20 community survey. J Epidemiol Community Health 1983 37: $180-6$.

16 Corrao WM, Braman SS, Irwin RS. Chronic cough as the sole presenting manifestation of bronchial asthma. $N$ Engl J Med 1979; 300: 633-7.

${ }^{17}$ Dobbs J, Marsh A. Smoking among secondary schoo children. London: HMSO, 1983.

${ }^{18}$ Goldstein BD, Melia RJW, Chinn S, Florey C du V, Clark $\mathrm{D}, \mathrm{John} \mathrm{HH}$. The relation between respiratory illness ir primary schoolchildren and the use of gas for cooking: II - Factors affecting nitrogen dioxide in the home. Int $J$ Epidemiol 1979; 8: 339-45.

${ }^{19}$ Schenker MB, Samet JM, Speizer FE. Risk factors for childhood respiratory disease. Am Rev Respir Dis 1983; 128: $1038-43$.

${ }^{20}$ Ferris BG, Ware JH, Berkey CS, Dockery DW, Spiro A, Speizer FE. Effects of passive smoking on health of children. Env Health Perspectives 1985; 62: 289-95.

${ }^{21}$ Bonham GS, Wilson RW. Children's health in families with cigarette smokers. Am J Public Health 1981; 71: 290-3.

22 Hasselblad V, Humble CG, Graham MG, Anderson Hs. Indoor environmental determinants of lung function in children. Am Rev Resp Dis 1981; 123: 479-85.

Accepted for publication February 1988 